\title{
An Algorithm for Computing All Berge Equilibria
}

\author{
H. W. Corley ${ }^{1}$ and Phantipa Kwain ${ }^{2}$ \\ ${ }^{1}$ Center On Stochastic Modelling, Optimization, and Statistics (COSMOS), The University of Texas at Arlington, \\ P.O. Box 19017, Arlington, TX 76019-0017, USA \\ ${ }^{2}$ TransSolutions, LLC., 14600 Trinity Boulevard, Fort Worth, TX 76155, USA
}

Correspondence should be addressed to H. W. Corley; corley@uta.edu

Received 31 August 2014; Accepted 13 January 2015

Academic Editor: Walter Briec

Copyright (C) 2015 H. W. Corley and P. Kwain. This is an open access article distributed under the Creative Commons Attribution License, which permits unrestricted use, distribution, and reproduction in any medium, provided the original work is properly cited.

An algorithm is presented in this note for determining all Berge equilibria for an $n$-person game in normal form. This algorithm is based on the notion of disappointment, with the payoff matrix (PM) being transformed into a disappointment matrix (DM). The DM has the property that a pure strategy profile of the PM is a BE if and only if $(0, \ldots, 0)$ is the corresponding entry of the $\mathrm{DM}$. Furthermore, any $(0, \ldots, 0)$ entry of the $\mathrm{DM}$ is also a more restrictive Berge-Vaisman equilibrium if and only if each player's $\mathrm{BE}$ payoff is at least as large as the player's maximin security level.

\section{Introduction}

In a Berge equilibrium (BE) for an $n$-person game, every $n-1$ player has pure strategies that maximized the remaining player's payoff. The BE was intuitively defined for pure strategies in [1] as a refinement to the Nash equilibrium (NE) [2]. The BE was formalized in [3] as a game-theoretic solution concept modeling mutual support and cooperation, as opposed to the selfishness of the NE. However, the BE was not studied extensively until recently. For example, see [4-9]. Only $[6,7]$ offer approaches for obtaining BEs, though, and these methods are stated abstractly without examples.

A simple algorithm is presented here for computing all BEs for an $n$-person game $G=\left(N,\left(S_{i}\right)_{i \in N},\left(u_{i}\right)_{i \in N}\right)$ in normal form, with $N=\{1, \ldots, n\}$ the set of players, $S_{i}$ the finite set of pure strategies for player $i$, and $u_{i}\left(s_{1}, \ldots, s_{n}\right)$ the von Neumann-Morgenstern utility of player $i$ for a pure strategy profile $s=\left(s_{1}, \ldots, s_{n}\right) \in \times_{j \in N} S_{j}=S$. The BE is defined as follows, where an incomplete strategy profile $s_{-i}=$ $\left(s_{1}, \ldots, s_{i-1}, s_{i+1}, \ldots, s_{n}\right)$ denotes a member of $S_{-i}=\times_{j \in N \backslash\{i\}} S_{j}$.

Definition 1. The strategy profile $s^{*}$ is a $\mathrm{BE}$ of $G$ if and only if

$$
u_{i}\left(s^{*}\right)=\max _{s_{-i} \in S_{-i}} u_{i}\left(s_{i}^{*}, s_{-i}\right) \quad \forall i \in N \text {. }
$$

The BE $s^{*}$ is further called a Berge-Vaisman equilibrium (BVE) if and only if the maximin security levels $\alpha_{i}$ of the players satisfy

$$
\alpha_{i}=\max _{s_{i} \in S_{i}} \min _{s_{-i} \in S_{-i}} u_{i}\left(s_{i}, s_{-i}\right) \leq u_{i}\left(s^{*}\right) \quad \forall i \in N
$$

so that no player is guaranteed better payoff than that given by $s^{*}$.

In Section 2 we define the disappointment matrix (DM) corresponding to the payoff matrix (PM) for $G$ and prove that a pure strategy $s^{*}$ is a $\mathrm{BE}$ if and only if $(0, \ldots, 0)$ is the corresponding entry of the DM. In Section 3 the approach of Section 2 is formalized as an algorithm to obtain all BEs and BVEs for G. In Section 4 a computational example is presented for $n=3$.

\section{The Disappointment Matrix}

The disappointment function is defined as a transformation of a player's payoffs to losses. 

(1) $1 \leftarrow i, 1 \leftarrow j$
(2) While $i \leq n$ do
(3) While $j \leq m_{j}$ do
(4) Compute $d_{i}\left(s_{i}^{j}, s_{-i}\right)$ for all $s_{-i} \in S_{-i}$ from (3).
(5) $d_{i}\left(s_{i}^{j}, s_{-i}\right) \leftarrow u_{i}\left(s_{i}^{j}, s_{-i}\right)$ for all $s_{-i} \in S_{-i}$
(6) End While
(7) End While
(8) $\mathbf{B E}=\bigcup\left\{s \in S: d_{i}(s)=0, i=1, \ldots, n\right\}$.
(9) $\mathbf{B V E}=\left\{s \in \mathbf{B E}: \alpha_{i} \leq u_{i}(s), i=1, \ldots, n\right\}$.

Algorithm 1

Definition 2. For the game $G$, the disappointment incurred by any player $i$ choosing $s_{i}$ and the other $n-1$ players choosing $s_{-i}$ is defined as

$$
\begin{array}{r}
d_{i}(s)=d_{i}\left(s_{i}, s_{-i}\right)=\max _{t_{-i} \in S_{-i}} u_{i}\left(s_{i}, t_{-i}\right)-u_{i}\left(s_{i}, s_{-i}\right) \\
\forall i \in N .
\end{array}
$$

The disappointment incurred by player $i$ for a strategy profile $s=\left(s_{i}, s_{-i}\right)$ is thus the difference between the best payoff that player $i$ could obtain by choosing $s_{i}$ and the actual payoff that player $i$ would obtain for the strategy profile $\left(s_{i}, s_{-i}\right)$. This definition immediately gives the following result.

Theorem 3. The pure strategy profile $s^{*}$ is a BE for the game $G$ if and only if the disappointment $d_{i}\left(s^{*}\right)=0$ for all $i \in N$. Moreover, a BE $s^{*}$ is also a BVE if and only if $\alpha_{i} \leq u_{i}\left(s^{*}\right)$ for all $i \in N$.

Proof. The strategy profile $s^{*}$ is a BE if and only if it satisfies (1) of Definition 1. However, (1) holds if and only if $d_{i}\left(s^{*}\right)=0$ in (3) for all $i \in N$. To complete the proof, the $\mathrm{BE} s^{*}$ is also a BVE if and only if it satisfies (2).

The DM of a game is now defined.

Definition 4. The disappointment matrix of $G$ is the matrix obtained from its PM by replacing $\left(u_{1}(s), \ldots, u_{n}(s)\right)$ by $\left(d_{1}(s), \ldots, d_{n}(s)\right)$ for all $s \in S$.

\section{Algorithm}

Consider the game $G$ in which each player $i \in N$ has $m_{i}$ pure strategies. Denote the $j$ th strategy of player $i$ by $s_{i}^{j}$, $j=1, \ldots, m_{i}$. Algorithm 1 describes the algorithm BECOMP for obtaining all BEs and BVEs for $G$ from its DM. The computational complexity of BECOMP is $O\left(n \prod_{i=1}^{n} m_{i}\right)$ because of the unavoidable enumeration in Step 4 of all strategy profiles $\left(s_{i}^{j}, s_{-i}\right), j=1, \ldots, m_{i}$, for each player $i$.

\section{Example}

For $n=3$ we use the notation of BECOMP with $m_{1}=m_{2}=$ $m_{3}=2$ and consider the game $G$ with a PM of Table 1 . The DM for $G$ is obtained from the PM via BECOMP and
TABLE 1: PM for $G$.

\begin{tabular}{lcccc}
\hline & \multicolumn{4}{c}{ Player 3 } \\
Player 1 & \multicolumn{2}{c}{$s_{3}^{1}$} & \multicolumn{2}{c}{$s_{3}^{2}$} \\
& \multicolumn{2}{c}{ Player 2 } & \multicolumn{2}{c}{ Player 2 } \\
& $s_{2}^{1}$ & $s_{2}^{2}$ & $s_{2}^{1}$ & $s_{2}^{2}$ \\
\hline$s_{1}^{1}$ & $(3,1,2)$ & $(3,4,0)$ & $(6,3,0)$ & $(3,5,1)$ \\
$s_{1}^{2}$ & $(1,4,5)$ & $(2,2,3)$ & $(2,4,4)$ & $(-1,2,3)$ \\
\hline
\end{tabular}

TABLE 2: DM for $G$.

\begin{tabular}{lcccc}
\hline & \multicolumn{3}{c}{ Player 3 } \\
Player 1 & \multicolumn{2}{c}{$s_{3}^{1}$} & \multicolumn{2}{c}{$s_{3}^{2}$} \\
& $s_{2}^{1}$ & $s_{2}^{2}$ & $s_{2}^{1}$ & $s_{2}^{2}$ \\
\hline$s_{1}^{1}$ & $(3,3,3)$ & $(3,1,5)$ & $(0,1,4)$ & $(3,0,3)$ \\
$s_{1}^{2}$ & $(1,0,0)$ & $(0,3,2)$ & $(0,0,0)$ & $(3,3,1)$ \\
\hline
\end{tabular}

shown in Table 2 . The unique BE for $G$ is $s^{*}=\left(s_{1}^{2}, s_{2}^{1}, s_{3}^{2}\right)$ with associated payoffs $\left(u_{1}\left(s^{*}\right), \ldots, u_{n}\left(s^{*}\right)\right)=(2,4,4)$. However, $s^{*}$ is not a BVE since $\alpha_{1}=3>u_{1}\left(s^{*}\right)=2$. Player 1 is guaranteed better payoff by choosing $s_{1}^{1}$ instead of $s_{1}^{2}$.

\section{Conflict of Interests}

The authors declare that there is no conflict of interests regarding the publication of this paper.

\section{References}

[1] C. Berge, Théorie Générale des Jeux à n Personnes, GauthierVillars, Paris, France, 1957.

[2] J. Nash, "Equilibrium points in $n$-person games," Proceedings of the National Academy of Sciences of the United States of America, vol. 36, pp. 48-49, 1950.

[3] V. Zhukovskii, "Some problems of nonantagonistic differential games," in Matematiceskie Metody v Issledovanii Operacij, P. Kenderov, Ed., pp. 103-195, Bulgarian Academy of Sciences, 1985.

[4] K. Y. Abalo and M. M. Kostreva, "Some existence theorems of Nash and Berge equilibria," Applied Mathematics Letters, vol. 17, no. 5, pp. 569-573, 2004.

[5] R. Nessah, M. Larbani, and T. Tazdaï, "A note on Berge equilibrium," Applied Mathematics Letters, vol. 20, no. 8, pp. 926-932, 2007.

[6] A. M. Colman, T. W. Körner, O. Musy, and T. Tazdaï, "Mutual support in games: some properties of Berge equilibria," Journal of Mathematical Psychology, vol. 55, no. 2, pp. 166-175, 2011.

[7] O. Musy, A. Pottier, and T. Tazdait, "A new theorem to find Berge equilibria," International Game Theory Review, vol. 14, no. 1, Article ID 1250005, 2012.

[8] A. Pottier and R. Nessah, "Berge-Vaisman and Nash equilibria: transformation of games," International Game Theory Review, vol. 16, no. 4, Article ID 1450009, 8 pages, 2014.

[9] M. Deghdak, "On the existence of Berge equilibrium with pseudocontinuous payoffs," ROMAII Journal, vol. 10, no. 1, pp. 25-37, 2014. 


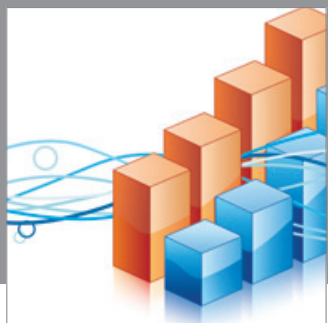

Advances in

Operations Research

mansans

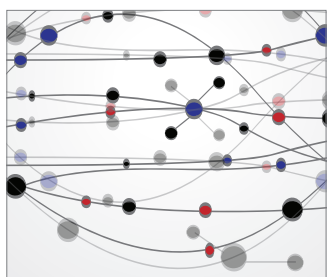

The Scientific World Journal
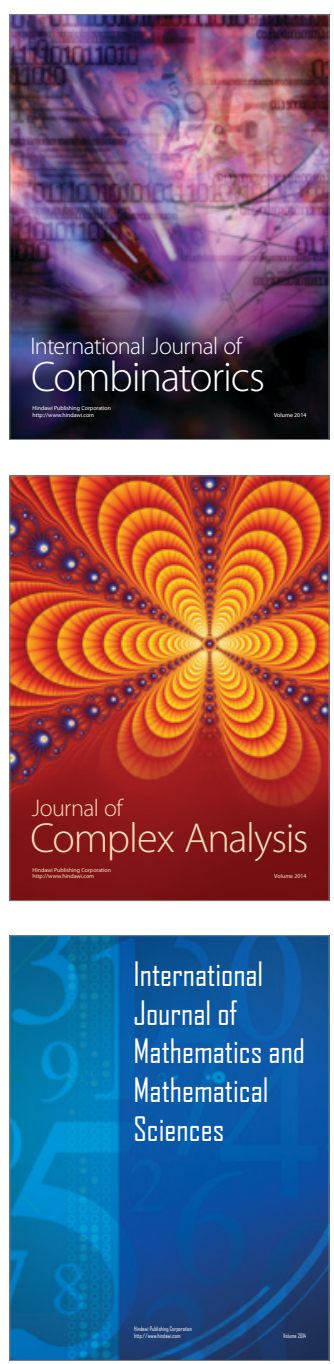
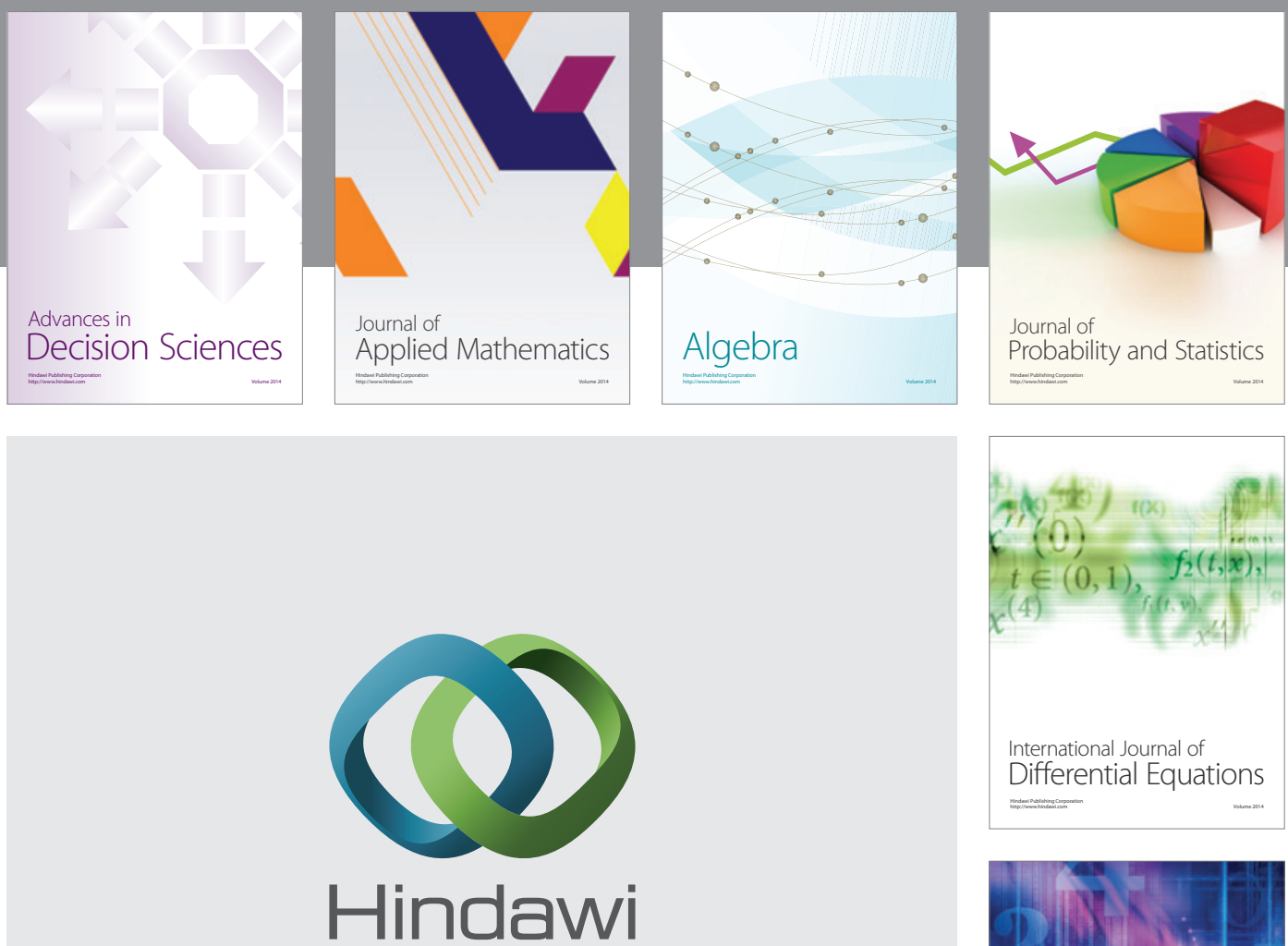

Submit your manuscripts at http://www.hindawi.com
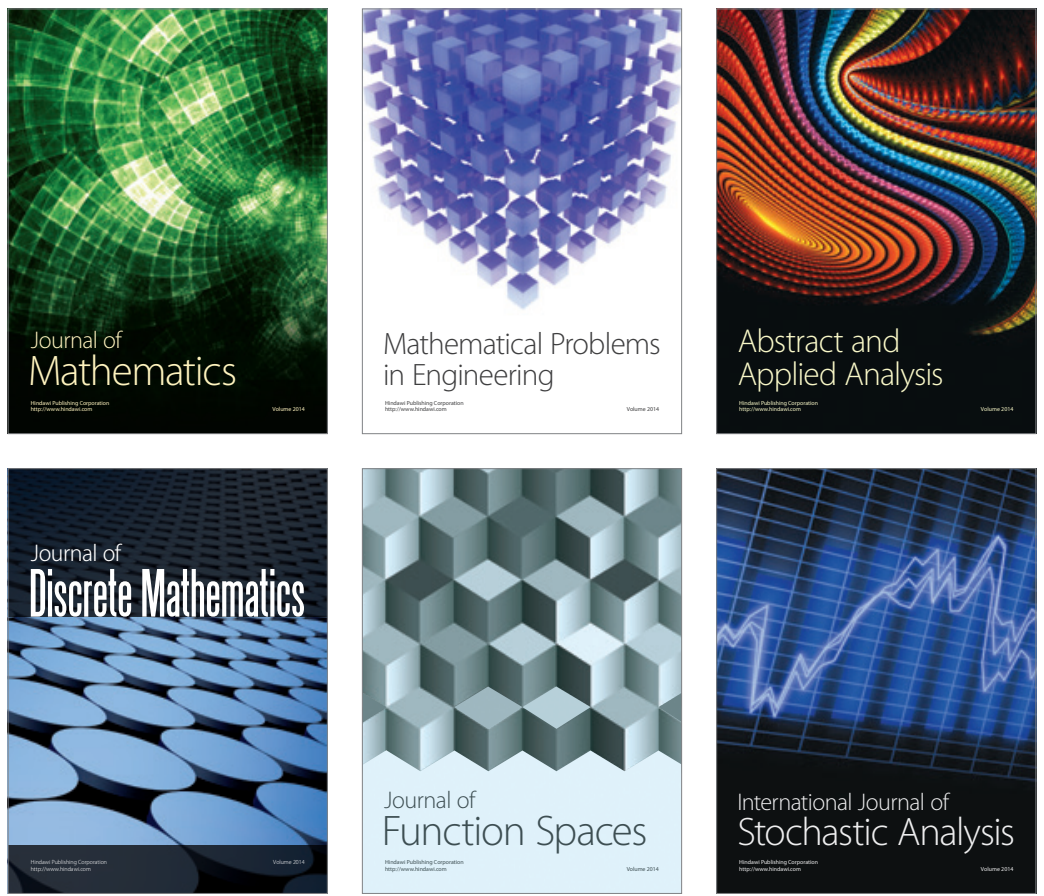

Journal of

Function Spaces

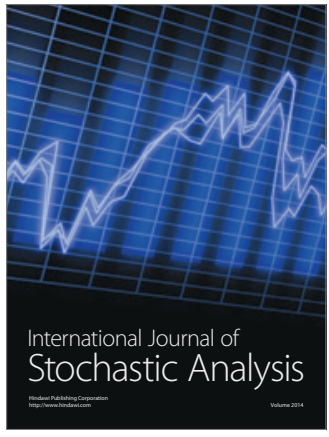

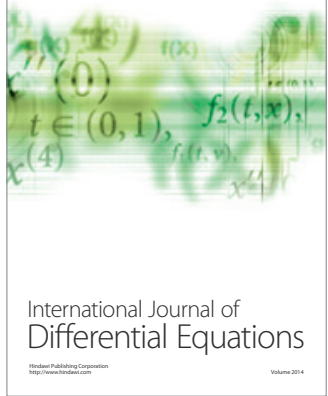
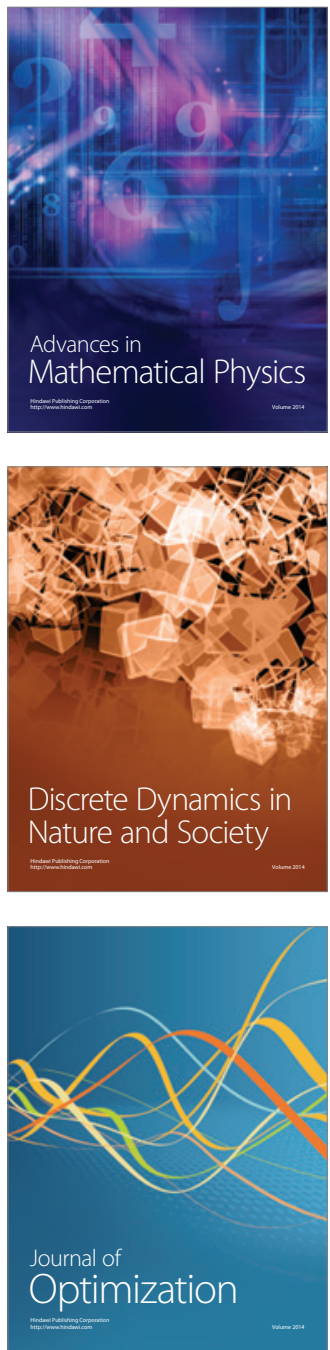